\title{
Engineering of Ramie - A Potential Textile Fibre for the Future
}

\author{
SK Dey* \\ Central Institute for Research on Cotton Technology, India \\ *Corresponding author: SK Dey, Former Senior Scientist, ICAR-Central Institute for Research on Cotton Technology, Adenwala Road, Matunga, \\ Mumbai, MAHARASTRA, INDIA
}

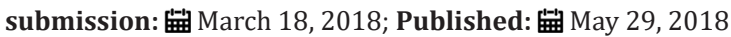

\begin{abstract}
Ramie, one of the oldest textile fibres of plant origin has from time immemorial ruled the textile world as king of natural fibres. Its popularity in the textile world is limited due to the difficulty in degumming and lack of knowledge of mechanical processing. Major natural conventional fibres like cotton, wool, silk and jute are widely used throughout the world. Apart from these, unconventional natural fibres like ramie, pineapple, sisal and hemp are grown in much smaller quantities and have local economic importance. Ramie, a lingo-cellulosic bast fibre obtained by decortication from stem of the plant followed by degumming possesses high $\alpha$-cellulose and very little lignin. It possesses some advantageous physical and chemical properties while some demerits are encrusting gummy material, cohesiveness. If the apparent demerits can be masked, a diverse range of products can be engineered by exploiting the intrinsic properties of ramie. One of the ways of masking is blending of ramie with different natural fibres in order to achieve the best utilization of the positive attributes and to reduce the negative attributes. Thus, employing the chemical degumming method coupled with the improved spinning technique, blended ramie yarns can be developed for spinning of acceptable yarn qualities. Woven fabrics from ramie-jute were also found satisfactory.
\end{abstract}

\section{Introduction}

Increasing ecological consciousness has accelerated interest in ramie originating from plants that are safe, biodegradable and recyclable. Ramie is one such natural lingo-cellulosic strong, lustrous and fine bast fibre obtained from the inner bark of Boehmeria (L) gaud. Research to evaluate the response of this fibre to degumming, mechanical processing and chemical processing operations is thus desirable7. The fibres are embedded in the cells of the bast, which lies between the outer bark and woody core of the stem. The fine spinnable fibres, fixed together by encrusting gummy materials pose some limitation and difficulties in fine spinning [14]. Therefore, this adhered gum needs to be removed by the process of degumming. Its popularity in the textile industry is limited due to the difficulty of degumming and lack of knowledge of mechanical processing $[5,6]$. The fibre possesses excellent tenacity, enhanced wet strength, silky lustre and excellent microbial resistance. Rapid wetting and quick drying are its special characteristics. Chemically, ramie fibre contains $81-96 \% \alpha$-cellulose along with other constituents like wax, fats, gums etc and is easily dyeable to produce various colours. It is not normally possible to spin the fibre with $20-30 \%$ encrusting gummy material, which, therefore, needs to be removed by the process of degumming. The gum content should be brought down to at least $5 \%$ for good spin ability. Various methods of degumming have been reported in the literature for removal of gums from decorticated ramie fibres. These include both chemical and microbial methods $[1,2,7,8]$. Attempts have been made by various research workers to spin ramie either alone or in blends with jute, silk, viscose, polyester, wool using jute and woolen spinning systems $[2,3,9,10,11]$. Since no information on specialized spinning system for ramie in India is available, it will be much easier to promote ramie in any of the existing spinning systems, provided an appropriate processing technology is developed for the production and processing of ramie either alone or in blends with other fibres for producing finer yarn with improved properties which can widen the application of ramie fibre.

\section{Global scenario}

The total annual production of ramie is around 1,20,000 tonnes from an area of about 1,00,000 hectares with china as the largest producer followed by Brazil and the Philippines, South Korea, Taiwan and Thailand. Though the fibre is known from ancient times the cost of extraction and difficulties of processing the fibre acted as a deterrent to its wide use. Some of the advanced countries have developed the processing technique but most of them being covered under patents.

\section{India's picture}

It is cultivated to a small extent in North Eastern States and SubHimalayan West Bengal. Its cultivation has not expanded in India as expected due to high initial investment followed by late return 
and lack of infrastructural facilities for decortication, degumming and marketing. Recently an interest has been created in expanding ramie plantation in North eastern states to 2500 hectares through Ministry of Agriculture. The agricultural research findings of Central Research Institute for Jute and Allied fibres at its centre at Ramie Research station at Sorbhog, Assam reveal for profitable methods of cultivation and decortication while National Institute of
Research on Jute and Allied Fibre Technology had been engaged in unfolding the secret techniques of degumming and mechanical and chemical processing.

Weindling [12] in his long vegetable fibres has done the ranking of physical properties of different bast fibres which are highly essential for processing of textile fibre (Table 1).

Table 1: Ranking of physical properties of different textile fibre.

\begin{tabular}{|c|c|c|c|c|}
\hline Properties & $1^{\text {st }}$ Rank & $2^{\text {nd }}$ Rank & $3^{\text {rd }}$ Rank & $4^{\text {th }}$ Rank \\
\hline Durability & Ramie & Flax & Hemp & Jute \\
\hline Tensile Strength & Ramie & Hemp & Flax & Jute \\
\hline Length of fibre cells & Ramie & Flax & Hemp & Jute \\
\hline Cohesiveness & Flax & Hemp & Jute & Ramie \\
\hline Fineness & Ramie & Flax & Hemp & Jute \\
\hline Uniformity & Flax & Ramie & Hemp & Jute \\
\hline Pliability & Flax & Ramie & Jute & Hemp \\
\hline colour & Ramie & Flax & Hemp & Jute \\
\hline
\end{tabular}

\section{Processing of decorticated ramie}

Decorticated ramie contains $20-30 \%$ of a cemented material known as gum. It is not normally possible to spin the fibre with this encrusting gum but for economical reasons it may sometimes be necessary to spin the fibre without degumming. Due to the presence of cementing gum in decorticated ramie, fibre separation to the desired extent cannot be achieved simply by a mechanical processing system. Application of oil-in-water emulsion on decorticated ramie was also not sufficient for spinning yarn of linear density below 140tex due to insufficient fibre splitting and stickiness of the fibre which caused lapping around rollers. Hence softening treatment with a suitable agent is essential before spinning. A technique has, therefore been developed by Mazumdar5 for spinning the decorticated ramie on jute/flax machinery largely available in India by soaking of fibre in water for 4-6 days and subsequent treatment with a cationic surfactant. Alternative method was application of jute batching emulsion on the fibre after the moisture is reduced to the desired level. The fibre at a moisture content of $25-30 \%$ was then passed through the conventional jute softener machine for kneading. Ply Yarns thus produced was suitable for sewing twines.

\section{Blending of ramie with natural and synthetic fibres}

NIRJAFT is the pioneering research Institute for blending of ramie with different natural and synthetic fibres. However, it is felt that such binary blending will help development of textiles with better functional properties by combining positive features of both the fibres. Development of appropriate technologies for processing of ramie either alone or in blends with other fibres can therefore widen the application of ramie fibre $[2-5,11]$. The present study explores the possibilities of producing degummed ramie fibre by chemical method and blending of this natural fibre with jute with the aim to develop the desired properties.

There is no specialized spinning system or industry for ramie but any system designed for cotton, wool, jute or silk can be adopted. Spinning is a multistage process which consists of three basic steps: Carding, Drawing and Spinning. The main difficulty in spinning ramie results from the combination of high tensile strength with longer fibre length and the breaker card can not break the fibre into staple lengths suitable for subsequent spinning. It is usually necessary to pass fibre through a stapling machine to obtain requisite staple lengths. For different spinning machines, different staple lengths of the fibre are required and this can be achieved by stapling or by mechanical sorting into basic length groups. Yarn preparations for the longer fibres are usually done on adaptations of machinery designed for wool fibres and for shorter fibres cotton system is adopted in America. Machinery adopted for flax and spun silk fibres are in use in China and the far east.

The spin ability of indigenous ramie fibre was assessed in the different spinning systems such as jute, cotton, wool and spun silk and flax system in collaboration with leading textile institutes.

\section{Processing ramie on jute spinning machinery}

The use of ramie for upgrading the performance of jute for making diversified natural products requires softening treatments like jute. It is clear that when jute batching emulsion is used during the softening treatment, the card droppings are comparatively lower in case of $20 \mathrm{~cm}$ stapled ramie. The spinning breaks / spindle are also lower compared to other softening treated fibre. When Kata softener/Anionic softener is used as a softening material, the tenacity goes on decreasing and the strength regularity of the yarn is increased. The surfactant may reduce the tenacity enhanced the strength C.V\% of the yarn due to enhanced slippage of filaments. This might be one of the causes of poor spinnability of degummed ramie as observed by Taylor and Herron for processing on cotton system [3].

\section{Jute-ramie blended yarn}

Spinning of jute with finer linear density pose some problem which can be avoided by blending to meet the global need of 
the value added and diversified products using bio-degradable natural fibre. A processing technology has been developed to make blended yarns out of degummed ramie and jute in conventional jute processing system with minor modifications. Incorporation of ramie in the blend with jute indicates that regularity of the blended yarn is better than control jute yarn. The reason may be better fineness of the ramie fibre which provides more number of fibres per unit cross section of the yarn. Control ramie yarn is superior in strength and extensibility than all jute yarn. In the blended yarn with increase in ramie component, the tenacity increases because the filament of ramie is stronger and finer than jute. The tenacity and breaking extension of ramie and ramie blended yarn increases markedly on wetting while the tenacity of all jute yarn decreases on wetting. Hence jute-ramie blended yarn can be used for the manufacture of diversified and value added products replacing jute (Figure 1).

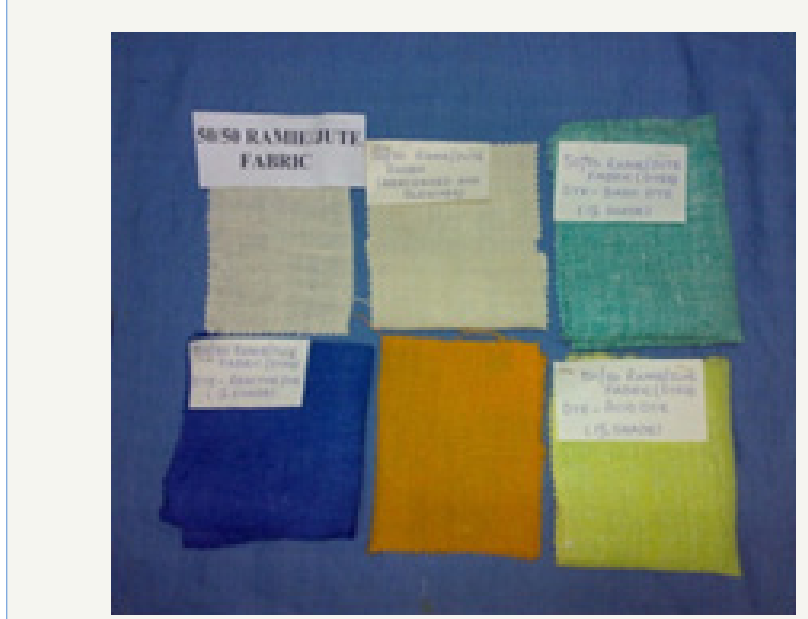

Figure 1: 50\% Ramie / 50\% Jute blended fabric.

Table 2: Properties of finer yarns from Ramie and Jute using ring spinning technology.

\begin{tabular}{|c|c|c|c|c|c|c|c|c|c|}
\hline \multirow{2}{*}{$\begin{array}{l}\text { Type of } \\
\text { Yarn }\end{array}$} & \multirow{2}{*}{$\begin{array}{c}\text { Linear } \\
\text { Density } \\
\text { (Tex) }\end{array}$} & \multicolumn{2}{|c|}{ Tenacity (Gm/Tex) } & \multicolumn{2}{|c|}{ Breaking Elongation (\%) } & \multirow[t]{2}{*}{ Um (\%) } & \multicolumn{3}{|c|}{ Imperfections / 100 Metre } \\
\hline & & Dry & Wet & Dry & Wet & & Thick & Thin & Neps \\
\hline Ramie & 65 & 27.24 & 32.69 & 3.95 & 4.46 & 4.46 & 26.38 & 77 & 81 \\
\hline jute & 125 & 10.04 & 9.92 & 1.96 & 2.18 & 27.29 & 27.29 & 97 & 63 \\
\hline
\end{tabular}

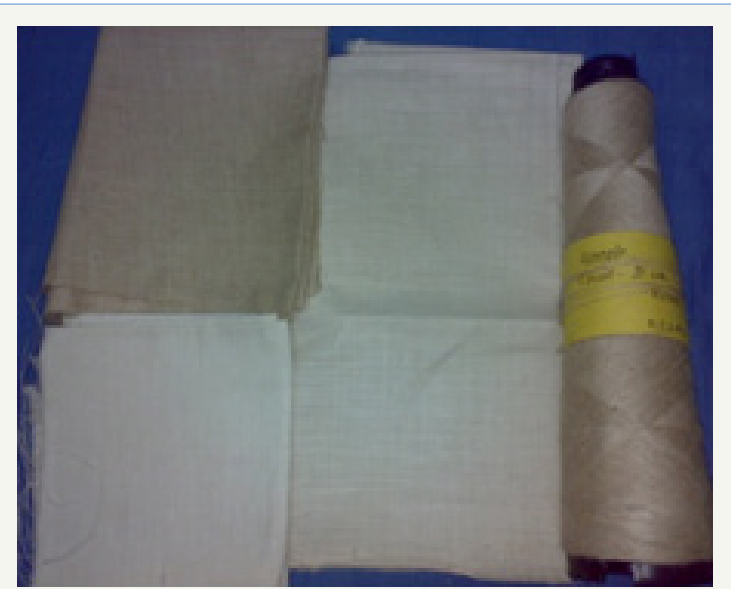

Figure 2: 100\% Ramie Yarn / Fabric using ring spinning technology.

Spinning of jute of finer counts poses some problem which can be avoided by using ring spinning technology to meet the global need of the value added diversified products using biodegradable natural fibre. The properties of finer yarns using ring spinning technology are given in Table 2. It is clear from the table that commercially degummed ramie can produce stronger and finer yarn. The tenacity is significantly higher compared to all jute yarn. This achievement can be used as a major breakthrough in the jute industry for the manufacturing of finer yarn. The yarn mass irregularity and imperfections are within reasonable limits (Figure 2).

\section{Conclusion}

In contemporary times, the pre-eminent position of ramie in textile applications is being seriously accepted with the spread in popularity of biodegradable lingo cellulosic fibre of plant origin. However, the encrusting gummy material of ramie is a serious limitation in the use of ramie as a useful textile material. Degumming of ramie fibre was done not only to remove the encrusting gummy material but simultaneously improve fibre properties and thereby it can be exploited commercially in any spinning system. Thus, by improved degumming method coupled with appropriate processing technology and proper selection of raw material, finer ramie and ramie blended yarns can be produced by adopting commercial spinning system. These yarns can be used for production of fabrics and knits on commercial machines and variety of outerwear garments.

\section{References}

1. Dasgupta PC, Sen K, Sen SK (1976) Cellul Chem Technol 10: 285.

2. Dey SK (2016) Performance of binary blends of indigenous ramieacrylic. Journal of Textile Science \& Engineering 6: 277-280.

3. Dey SK Operational optimization of ramie fibre processing. Doctoral Thesis, Jadavpur University, India.

4. Ahmed M, Chattopadhyay SK, Chapekar AK, Gaikwad RS, Dey SK (2004) Indian Journal of Fibre pp. 362-365.

5. Dey SK, Mukherjee SK, Bhattacharyya A (2003) Text Res J 73(12): 10621065.

6. Pandey SN, Mathew MD (1988) Text trends 30: 49. 
7. Luniak B (1954) Text quarterly 4(4): 92.

8. Paul NB, Bhattacharyya SK (1979) J Text Inst 70(12): 512.

9. Mazumdar MC (1972) J Text Association 33(4).

10. Mazumdar MC, Sen SK, Dasgupta PC (1975) Indian Text J 85(8): 135.
11. Dey SK, Bhattacharyya SK (2005) $20^{\text {th }}$ Indian engineering congress, Kolkata, India, p. 69.

12. Weindling L (1947) Long vegetable Fibres. Columbia University Press, New York, USA.

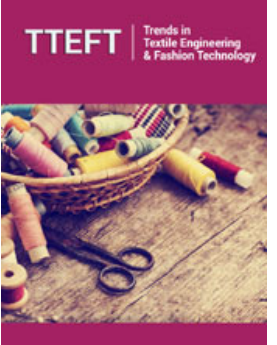

Trends in Textile Engineering \& Fashion Technology

\section{Benefits of Publishing with us}

- High-level peer review and editorial services

- Freely accessible online immediately upon publication

- Authors retain the copyright to their work

- Licensing it under a Creative Commons license

- Visibility through different online platforms 